\title{
Free thiomalate in plasma and urine of patients receiving sodium aurothiomalate
}

\author{
S.R.RUDGE,$^{1}$ D. PERRETT,$^{2}$ AND A. J. SWANNELL ${ }^{1}$ \\ From the ${ }^{1}$ Department of Rheumatology, City Hospital, Nottingham, and the ${ }^{2}$ Department of Medicine, St \\ Bartholomew's Hospital, London
}

SUMmaRY Free thiomalate is measureable in the plasma and urine of patients with rheumatoid arthritis receiving sodium aurothiomalate (Myocrisin). Plasma concentrations and urinary excretion of free thiomalate were measured in 8 patients by high-performance liquid chromatography and electrochemical detection. After an initial intramuscular dose of $20 \mathrm{mg}$ sodium aurothiomalate, free thiomalate was detected in plasma within $15 \mathrm{~min}$, peak levels of up to $600 \mathrm{nmol} / \mathrm{l}$ occurring at $30 \mathrm{~min}$. Plasma levels declined rapidly thereafter. During the first $24 \mathrm{~h}$ between 2 and $16 \%$ of the injected dose of aurothiomalate was recovered in the urine as free thiomalate, maximum excretion occurring during the first hour.

Although it is well recognised that only thiolcontaining gold compounds act as effective antirheumatic agents, ${ }^{1}$ the role of the thiol moiety in the activity of such compounds has been largely ignored. Jellum et al. suggested in 1977 that sodium aurothiomalate dissociates immediately following intramuscular injection to form free thiomalate and protein-bound gold. ${ }^{2}$ Their initial experiments were carried out in animals with double isotope labelled aurothiomalate $\left({ }^{195} \mathrm{Au}-{ }^{14} \mathrm{C}\right)$ and showed differential excretion of the 2 radiolabels. ${ }^{3}$ These experiments have recently been extended to man, but with only a single radiolabel $\left({ }^{14} \mathrm{C}\right) .{ }^{4}$ By means of gas chromatography and mass spectrometry Heinenger et al. detected but did not quantitate free thiomalate in the urine of patients with rheumatoid arthritis receiving sodium aurothiomalate. ${ }^{5}$ However, they were unable to demonstrate thiomalate in either serum or synovial fluid.

Thiol compounds have always proved difficult to quantitate in physiological fluids, because of both their inherent instability and the presence of endogenous thiols. The combination of highperformance liquid chromatography (HPLC) and electrochemical detection (ECD) has recently been shown to be a simple and rapid method for the detection of 2 thiol-containing drugs, D-penicillamine and captopril, in plasma and urine. ${ }^{6}$ We have recently developed a similar method for the detection of free

Accepted for publication 11 February 1983.

Correspondence to Dr S. R. Rudge, City Hospital, Hucknall Road, Nottingham NG5 1 PB. thiomalate. ${ }^{8}$ Here we describe the use of this technique to measure plasma and urinary levels of free thiomalate in 8 patients following their first injection of sodium aurothiomalate.

\section{Patients and methods}

Patients. Eight patients ( 7 females, 1 male) were studied. Seven had definite or classical rheumatoid arthritis according to ARA criteria ${ }^{9}$ and one had psoriatic arthritis. Their mean age was 45 years (range 28-67) with a mean disease duration of 3 years (range 1-6). None had previously received gold or D-penicillamine and none were currently receiving steroids. All were regularly taking nonsteroidal anti-inflammatory drugs.

Sampling procedure. After an overnight fast, control blood and urine samples were taken at $9.00 \mathrm{am}$ (time 0 ). An intramuscular injection of $20 \mathrm{mg}$ sodium aurothiomalate (Myocrisin) was then given. Blood samples were obtained by separate forearm venepuncture initially at $30,60,120$, and $240 \mathrm{~min}$; when the short half-life of plasma thiomalate became apparent, additional samples were taken at 15, 45, and $90 \mathrm{~min}$. Samples were collected into tubes containing disodium ethylenediaminetetra-acetic acid (EDTA), final concentration $5 \mathrm{mmol} / \mathrm{l}$, and centrifuged for $5 \mathrm{~min}$. Plasma proteins were precipitated by the addition of $200 \mu$ l of sulphosalcylic acid (2 $\mathrm{mol} / \mathrm{l}$ ) to $1 \mathrm{ml}$ of plasma. After a further $5 \mathrm{~min}$ centrifugation the supernatant was rapidly frozen and stored at $-20^{\circ} \mathrm{C}$ until analysis. Urine samples for the 

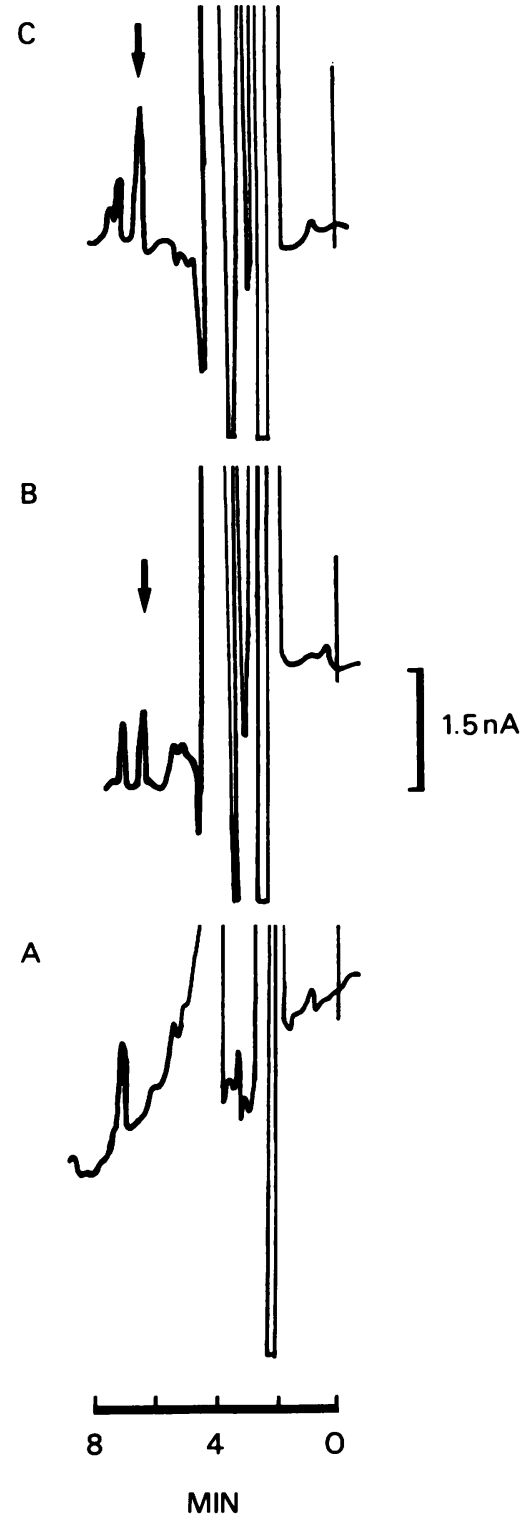

Fig. 1 Chromatograms showing the detection of thiomalate in plasma extract: A, before injection; B, 60 min following injection of $20 \mathrm{mg}$ sodium aurothiomalate; $\mathrm{C}$, as $\mathrm{B}$ but with added thiomalate. Broad arrows indicate thiomalate peaks.

periods $0-1 \mathrm{~h}, 1-2 \mathrm{~h}, 2-4 \mathrm{~h}$, and 4-24 h were collected directly into containers containing $6 \mathrm{~mol} / \mathrm{l} \mathrm{HCl}$ (1 $\mathrm{ml}$ per $100 \mathrm{ml}$ of urine). Urine volumes were measured and aliquots were then frozen at $-20^{\circ} \mathrm{C}$ until assay.
Thiomalate assay. Concentrations of free thiomalate were measured by HPLC and ECD at a gold electrode as previously described. ${ }^{8}$ Briefly, the chromatographic system comprised an ACS 300/01 pump (Applied Chromatography Systems) and an EDT electrochemical detector LCA-15 (EDT Research) equipped with a LC-19 gold cell (BioAnalytical Systems). The cell was maintained at $+0.60 \mathrm{~V}$ for urine and $+0.80 \mathrm{~V}$ for plasma, versus an $\mathrm{Ag} / \mathrm{AgCl}$ reference electrode. ${ }^{8}$ Separation of thiomalate from other sulphydryl-containing compounds was performed on a $100 \mathrm{~mm} \times 5 \mathrm{~mm}$ column packed with $3 \mu \mathrm{m}$ ODS Hypersil. The eluent consisted of a $0.1 \mathrm{~mol} / \mathrm{l}$ aqueous phosphate buffer $\mathrm{pH} 2$ containing $8 \%$ methanol for plasma samples and $1 \%$ methanol for urine samples. The detection limit for thiomalate in buffer using this technique was $\mathbf{4 0} \mathrm{fmol}$ injected on to the column $(\mathrm{S} / \mathrm{N}=2)$. Reproducibility was $2 \cdot 1 \%$ $(n=10)$, and the detector response was linear with increasing amounts of thiomalate injected $(r=0.99$, $\mathrm{p}<0.001$ ). Recovery of thiomalate added to plasma at $20^{\circ} \mathrm{C}$ and immediately deproteinated was $94.9 \pm$ $2 \cdot 0 \%(n=5)$. Recovery of thiomalate from urine was $94 \cdot 0 \pm 3 \cdot 5 \%(n=6)$.

Statistics. Data are presented as mean \pm 1 SEM.

\section{Results}

\section{P L A S M A}

Free thiomalate was detected in the plasma of seven of the 8 patients. Fig. 1 shows the presence of thiomalate in the plasma of a patient who had received 20 $\mathrm{mg}$ of sodium aurothiomalate by IM injection $60 \mathrm{~min}$ earlier; the concentration of thiomalate was 480 $\mathrm{nmol} / \mathrm{l}$. The thiomalate peak co-chromatographed with authentic thiomalate added to the same plasma (Fig. 1C).

Table 1 shows the plasma concentrations of free thiomalate in the 8 patients. Peak plasma levels were recorded between 30 and 45 minutes after injection of aurothiomalate and became undetectable by 4 hours. Mean concentrations are shown in Fig. 2.

UR IN E

Free thiomalate was found in the urine of all 8 patients, with levels shown in Table 1 ; maximum excretion usually occurred during the first hour. Mean thiomalate excretion is shown in Fig. 3.

The percentage (in molar terms) of the injected dose of sodium aurothiomalate recovered from the urine as thiomalate within the $24 \mathrm{~h}$ after injection was calculated; this varied between 2 and $16 \%$ (Table 1 ).

\section{Discussion}

In this study we have shown for the first time that free 
Table 1 Plasma and urinary thiomalate in eight patients receiving sodium aurothiomalate

\begin{tabular}{|c|c|c|c|c|c|c|c|c|c|c|c|c|c|c|}
\hline \multirow[t]{3}{*}{ Patient } & \multicolumn{8}{|c|}{ Plasma thiomalate concentration (nmol/l) } & \multicolumn{5}{|c|}{ Excretion of urinary thiomalate ( $\mu \mathrm{mol})$} & \multirow{3}{*}{$\begin{array}{l}\text { Urinary recovery (\%) } \\
\text { Molar recovery of } \\
\text { injected dose as thio- } \\
\text { malate within } 24 \text { hours }\end{array}$} \\
\hline & \multicolumn{8}{|c|}{ Time after injection of aurothiomalate ( $\mathrm{min}$ ) } & \multicolumn{5}{|c|}{$\begin{array}{l}\text { Period after injection of aurothiomalate } \\
\text { (hours) }\end{array}$} & \\
\hline & 0 & 15 & 30 & 45 & 60 & 90 & 120 & 240 & -0 & $0-1$ & $1-2$ & $2-4$ & $4-24$ & \\
\hline 1 & 0 & * & UD & * & 480 & * & 120 & UD & 0 & $4 \cdot 28$ & 0.43 & 0.43 & UD & $10 \cdot 1$ \\
\hline 2 & 0 & $*$ & UD & * & UD & * & UD & UD & 0 & 0.35 & $0 \cdot 59$ & $0 \cdot 22$ & 0.07 & $2 \cdot 4$ \\
\hline 3 & 0 & $*$ & 610 & $*$ & 350 & * & UD & UD & 0 & $1 \cdot 32$ & 0.92 & $0 \cdot 31$ & 0.10 & $5 \cdot 2$ \\
\hline 4 & 0 & $*$ & 498 & * & 186 & $*$ & UD & UD & 0 & 4.63 & $1 \cdot 14$ & $0 \cdot 28$ & 0.09 & $12 \cdot 0$ \\
\hline 5 & 0 & 252 & 282 & 318 & 216 & 48 & UD & UD & 0 & 0.84 & 0.09 & 0.07 & UD & $7 \cdot 8$ \\
\hline 6 & 0 & UD & 120 & 192 & 54 & UD & UD & UD & 0 & $2 \cdot 80$ & 0.86 & 0.37 & UD & $8 \cdot 0$ \\
\hline 7 & 0 & 75 & 225 & 175 & 250 & UD & UD & UD & 0 & $4 \cdot 21$ & $2 \cdot 50$ & 1.74 & UD & $16 \cdot 5$ \\
\hline 8 & 0 & 330 & 330 & 192 & 150 & 18 & UD & UD & 0 & $2 \cdot 90$ & 0.83 & UD & UD & $7 \cdot 3$ \\
\hline
\end{tabular}

*Not measured. UD = undetectable: detection limit for plasma is approximately $15 \mathrm{nmol} / 1$.

Each patient received $20 \mathrm{mg}$ sodium aurothiomalate $(51 \cdot 2 \mu \mathrm{mol})$ by intrasmuscular injection at time 0 .

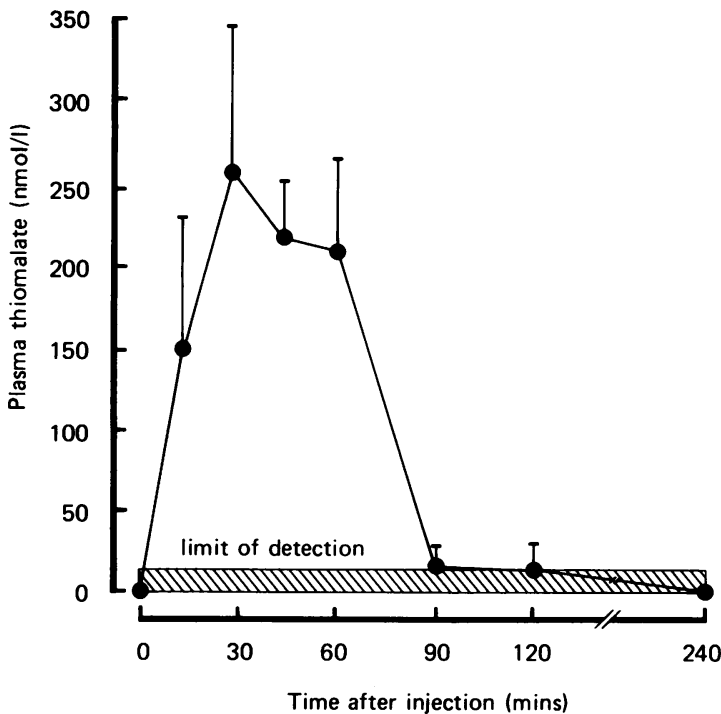

Fig. 2 Plasma concentrations of thiomalate following intramuscular injection of $20 \mathrm{mg}$ sodium aurothiomalate in 8 patients. Data are presented as mean $\pm S E M$.

thiomalate circulates in human plasma after intramuscular injection of sodium aurothiomalate. Thiomalate may be detected as early as 15 minutes after injection; peak plasma levels are attained within 45 minutes and thereafter it rapidly becomes undetectable. It is also easily measureable in urine.

HPLC and ECD provides a simple, highly sensitive, and reproducible method for the detection and measurement of free thiomalate in physiological fluids. The plasma concentrations we have shown, even at peak levels, are well below the limit of detec-

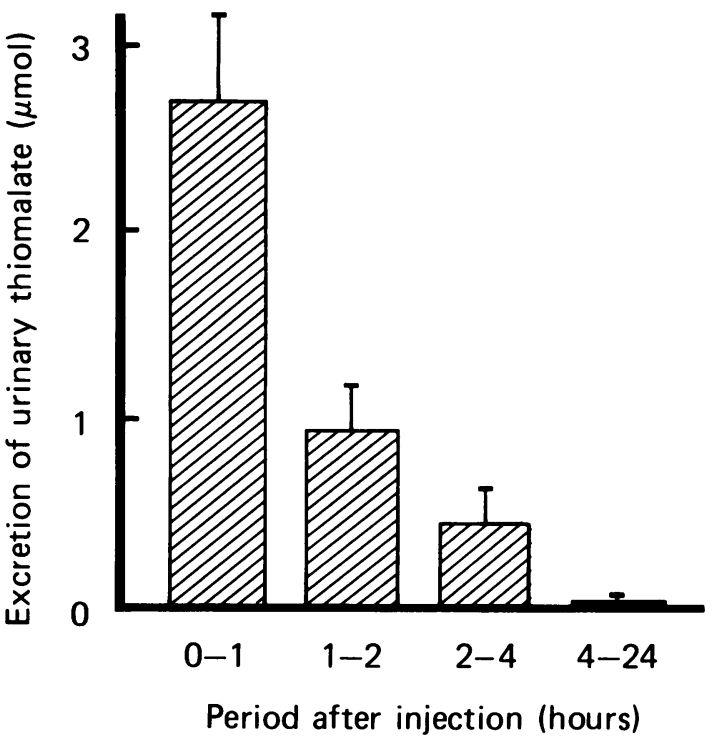

Fig. 3 Urinary excretion of thiomalate following injection of $20 \mathrm{mg}$ sodium aurothiomalate. Data are presented as mean $\pm S E M$.

tion of the assay techniques previously employed. ${ }^{5}$ Even so we were unable to detect thiomalate in the plasma of patient 2 . Since this patient's urinary excretion of thiomalate was the lowest recorded, plasma levels may have been below our limit of detection (approximately $15 \mathrm{nmol} / \mathrm{l}$ ).

In their recent report Jellum and Munthe demonstrated the rapid initial urinary excretion of the carbon label of ${ }^{14} \mathrm{C}$-labelled sodium aurothiomalate. ${ }^{4}$ After $24 \mathrm{~h}$ approximately $60 \%$ of the radioactivity had been recovered from the urine. The pattern of 
urinary excretion of free thiomalate seen in our 8 patients closely resembles that found by these workers, though our percentage recovery is much lower. This is probably because this assay measures only free thiomalate whereas the ${ }^{14} \mathrm{C}$ label employed by Jellum and Munthe, and identified by thin-layer chromatography, would represent both free thiomalate and its disulphide.

The similarity in chemical structure and clinical activity between thiomalic acid and several other thiol-containing second line antirheumatic agents, notably D-penicillamine, has been noted. ${ }^{12}$ Animal studies by Arrigoni-Martelli et al. ${ }^{10}$ and in-vitro work by Skosey and Chow ${ }^{11}$ indicate that thiomalic acid may have potent antirheumatic properties, while human studies by Munthe and Jellum ${ }^{12}$ suggest that oral sodium thiomalate without gold may be as effective as sodium aurothiomalate in the suppression of disease activity.

The demonstration of circulating free thiomalate in patients receiving intramuscular sodium aurothiomalate has several important implications. Firstly, it demonstrates that, as in patients receiving D-penicillamine, treatment with sodium aurothiomalate results in the circulation of a free thiol compound. Secondly, since thiomalic acid has been shown to possess antirheumatic properties, it suggests that some at least of the activity of sodium aurothiomalate may reside in its thiol moiety. Finally, the ability to measure plasma and urinary levels of this potentially active metabolite will be of considerable value in its further investigation.

Further work is necessary to define the metabolites of thiomalate; by analogy with D-penicillamine these would include the internal and mixed disulphides, which our present assay does not measure. For D-penicillamine these represent the most abundant circulating forms. ${ }^{13} \mathrm{~A}$ controlled trial of sodium thiomalate without gold is also clearly indicated.
We thank Professor C. J. Dickinson, Medical College of St Bartholomew's Hospital, for provision of laboratory facilities and Dr D. H. Bossingham, City Hospital Nottingham, for allowing us to study his patients. S.R.R. is supported by a grant from the Arthritis and Rheumatism Council.

\section{References}

1 Jaffe I A. Thiol compounds with penicillamine-like activity and possible mode of action in rheumatoid arthritis. Clin Rheum Dis 1980; 6: 633-45.

2 Jellum $\mathrm{E}$, Aaseth $\mathrm{J}$, Munthe $\mathrm{E}$. Is the mechanism of action during treatment of RA with penicillamine and gold thiomalate the same? Proc $R$ Soc Med 1977; 70 (suppl 3): 136-9.

3 Jellum E, Munthe E. Fate of the gold and the thiomalate part after intramuscular administration of aurothiomalate to mice. Ann Rheum Dis 1980; 39: 155-8.

4 Jellum E, Munthe E. Fate of the thiomalate part after intramuscular administration of aurothiomalate in rheumatoid arthritis. Ann Rheum Dis 1982; 41: 431-2.

5 Heinenger J, Munthe E, Pahle J, Jellum E. Capillary column gas chromatography-mass spectrometry in studies on rheumatoid arthritis. J Chromatogr 1978; 158: 297-304.

6 Saetre R, Rabenstein D L. Determination of penicillamine in blood and urine by high performance liquid chromatography. Anal Chem 1978; 50: 276-80.

7 Perrett D, Drury P L. Determination of captopril in physiological fluids using high performance liquid chromatography with electrochemical detection. J Liq Chromatogr 1982; 5: 97-110.

8 Rudge S R, Perrett D, Drury P L, Swannell A J. Determination of thiomalate in physiological fluids using high performance liquid chromatography and electrochemical detection. J Pharmaceut Biomed Anal in press.

9 Ropes M W, Bennett G A, Cobb S, Jacox R F, Jessar R A. Revision of diagnostic criteria for rheumatoid arthritis. Bull Rheum Dis 1958; 9: 175-6.

10 Arrigoni-Martelli E, Bramm E, Binderup L. Dpenicillamine-like activity of thiols. Eur J Rheumatol Inflamm 1978; 1: 197-203.

11 Skosey J L, Chow D C. Protection by D-penicillamine, gold salts and other drugs of proteinase inhibitor from oxidative damage: a mechanism for the prevention of inflammatory tissue damage. Proceedings of the 15th International Congress of Rheumatology, Paris 1981. Abstract 121.

12 Munthe E, Jellum E. Tolerance and effectiveness of sodium thiomalate without gold in rheumatoid arthritis. Scand $J$ Rheumatol 1980; suppl 33: 21 (abstr).

13 Perrett D. The metabolism and pharmacology of D-penicillamine in man.J Rheumatol 1981; 8 (suppl 7): 41-50. 